\title{
Early vertical distribution of roots and its association with drought tolerance in tropical maize
}

\section{Journal Article}

Author(s):

Grieder, Christoph; Trachsel, Samuel; Hund, Andreas (1)

Publication date:

2014-04

Permanent link:

https://doi.org/10.3929/ethz-b-000082790

Rights / license:

In Copyright - Non-Commercial Use Permitted

Originally published in:

Plant and Soil 377(1-2), https://doi.org/10.1007/s11104-013-1997-1 


\title{
Early vertical distribution of roots and its association with drought tolerance in tropical maize
}

\author{
C. Grieder • S. Trachsel • A. Hund
}

Received: 12 September 2013 / Accepted: 27 November 2013 /Published online: 29 December 2013

C) Springer Science+Business Media Dordrecht 2013

\begin{abstract}
Background and aims Selection for deep roots to improve drought tolerance of maize (Zea mays L.) requires presence of genetic variation and suitable screening methods.

Methods We examined a diverse set of 33 tropical maize inbred lines that were grown in growth columns in the greenhouse up to the 2-, 4-, and 6-leaf stage and in the field in Mexico. To determine length of roots from different depths at high throughput, we tested an approach based on staining roots with methylene blue and measuring the amount of absorbed dye as proxy measure for root length.

Results Staining provided no advantage over root weights that are much easier to measure and therefore preferable. We found significant genotypic variation for all traits at the 6-leaf stage. For development rates between the 2-leaf and the 6-leaf stage, genotypes only differed for rooting depth and the number of crown
\end{abstract}

Responsible Editor: Alexia Stokes.

Electronic supplementary material The online version of this article (doi:10.1007/s11104-013-1997-1) contains supplementary material, which is available to authorized users.

C. Grieder $\cdot$ A. Hund $(\bowtie)$

Institute of Agricultural Sciences, ETH Zurich,

Universitätstrasse 2, 8092 Zurich, Switzerland

e-mail: andreas.hund@ipw.agrl.ethz.ch

S. Trachsel

International Maize and Wheat Improvement Center

CIMMYT,

Mexico 06600 DF, Mexico roots. Positive correlations of leaf area with root length and rooting depth indicated a common effect of plant vigor. However, leaf area in growth columns was negatively related to grain yield under drought $(r=-0.50)$. Conclusion The selection for deeper roots by an increase in plant vigor likely results in a poorer performance under drought conditions. The proportion of deep roots was independent of other traits but showed a low heritability and was not correlated to field performance. An improved screening protocol is proposed to increase throughput and heritability for this trait.

Keywords Tropical maize $\cdot$ Rooting depth $\cdot$ Growth column $\cdot$ Shoot-root relations

\section{Introduction}

Desiccation avoidance is one possible strategy of plants to cope with drought and is mainly associated with minimization of water loss and/or the maximization of water uptake (Ludlow and Muchow 1990). The amount of accessible soil water is strongly determined by the plant's root morphology and architecture. Deeper soil layers are seen as a potent source of crop water in many semi-arid zones (Van Staveren and Stoop 1985). The formation of a deep root system would give access to this water sources, allowing the plant to avoid desiccation during drought events (Ludlow and Muchow 1990). In wheat, Kirkegaard et al. (2007) obtained a surplus of $0.62 \mathrm{t} / \mathrm{ha}$ grain yield from an additional $10.5 \mathrm{~mm}$ of subsoil water under drought conditions. In 
maize, simulation studies (Hammer et al. 2009) highlighted the importance of a deep root system for increased water and nutrient acquisition as well as yield formation. Co-localization of quantitative trait loci (QTL) for root parameters (e.g. crown root angle, axile root growth rate) with traits related to yield in maize and sorghum (Trachsel et al. 2009; Hund et al. 2011; Mace et al. 2012) further emphasized the importance of root morphology and architecture for water acquisition.

Since the formation of root meristems requires considerable amounts of carbon (Lynch et al. 2005), resource (i.e. water) rich soil regions need to be explored at the expense of less resource rich regions (Hodge 2009). Root systems with fewer lateral roots in the topsoil but deep-reaching axile roots are more efficient in extracting water from deeper soil strata (Hund et al. 2009a). In accordance, Bolanos et al. (1993) reported a $33 \%$ reduction in root biomass in the upper soil after eight cycles of recurrent selection under drought conditions, although rooting depth in general did not increase. The relative distribution of roots within the soil profile therefore seems to play an important role, with the most densely rooted soil layer affecting drought tolerance more than total rooting depth (Yu et al. 2007).

Root parameters are traits that are typically difficult to phenotype (Hund et al. 2011). A way to deal with this problem in the field is to describe the root system by a "shovelomics" approach that is based on few traits (e.g. crown root number and angle) that can be easily determined at the stem base (Trachsel et al. 2011), or to use other measures like root pulling force (Lebreton et al. 1995), root capacitance (Beem et al. 1998) or soil coring (Watt et al. 2013). On the other extreme, plants can be grown completely out of soil, e.g. in hydroponics (Tuberosa et al. 2002), growth pouches (Bonser et al. 1996; Hund et al. 2009b) or in paper rolls (Zhu et al. 2005; Kumar et al. 2012), facilitating the complete and non-destructive assessment of the root system up to a limited growth stage. However, both types of systems do not allow to assess the distribution of the root system within its natural environment (i.e. field soil), or only give proxy measures for the same (e.g. root angles measured in shovelomics are indicative for rooting depth (Trachsel et al. 2011)). Using pots or growth columns filled with a soil substrate is a compromise. Compared to out-of-soil systems, the measurement throughput is reduced but plants can be grown to later growth stages to avoid seed effects observed for evaluations at early stages (Pommel and Bouchard 1990).
Compared to field grown plants, the complete root system may be assessed in growth columns, although the root environment may be different than in a field soil.

The two most commonly used methods to assess the vertical distribution of root length within the soil are root washing and minirhizotron imaging (Pierret et al. 2005). In case of washing, roots are usually collected from different depth increments to obtain the vertical distribution of their lengths. To test for treatment differences, the simplest approach is to compare among samples taken from the same depth segment, leading to as many comparisons as there are soil sections. To summarize such data, some authors chose arbitrary thresholds to quantify the roots below a certain depth (Yadav et al. 1997; Kato et al. 2006; Araki et al. 2000). Other approaches are based on linear or non-linear models approximating the vertical root distribution (Hao et al. 2005), of which the parameters could be used to summarize treatment effects. However, we are not aware that this approach has been taken for routine comparison among genotypes. The reason for this may lie in the difficulty to fit parsimonious models with meaningful parameters to a population of differently shaped distributions. An elegant approach to summarize data from soil profiles was used by Schenk and Jackson (2002) who fitted a non-linear smoothing function to each profile and reported the depth at which either $50 \%$ $\left(D_{50}\right)$ or $95 \%\left(D_{95}\right)$ of the roots were located by means of interpolations. Hund et al. (2009a) adapted this approach but noted that $\mathrm{D}_{50}$ and $\mathrm{D}_{95}$ were strongly correlated. The authors proposed to use a new deep root ratio (DR) which measures the proportion of roots located in the lower part of the root system, i.e. those located below half the depth given by $\mathrm{D}_{95}$. Based on these parameters, genotypes were identified that differed with regard rooting depth $\left(\mathrm{D}_{95}\right)$, root distribution (DR) or both.

Determining the length of excavated roots is a limiting step in a growth column system. Determining root dry weight is fast, but due to the varying diameter of different root types, it only gives an approximate measure for root length. For example, Hund et al. (2004) showed that lateral roots of different genotypes contributed differently to overall root size. Analysis of digital root images (produced by photography or scanning) by appropriate software is fast and precise, but displaying roots for image acquisition is a tedious work, still limiting throughput of this method. Sattelmacher et al. 
(1983) proposed a rapid method to measure root surface by staining roots with a dye, resolving the absorbed dye into a solution, and measuring the optical absorption of this solution as proxy for root surface area and length. Adoption of such a staining method might help to determine root length with reasonable precision and speed and, therefore, improve the efficiency of a growth column system for root distributional phenotyping.

Genotypic variation for rooting depth and its association to water uptake in maize has been shown in different studies (Lorens et al. 1987; Wan et al. 2000; Hund et al. 2009a; Manavalan et al. 2011). However, most of these studies were based only on few genotypes or did not examine root distribution in the soil profile. The objectives of this study were to i) compare different methodologies to determine the vertical distribution of root length of maize plants grown in growth columns, ii) assess the genetic diversity for root morphology and vertical distribution in a diverse panel of 33 tropical maize inbred lines from the heterotrophic (2-leaf) until early autotrophic (6-leaf) growth stage, and iii) examine allometric relationships among root- and shoot parameters determined in the growth columns and their relationship with grain yield measured under drought in the field.

\section{Material and methods}

\section{Genetic material}

Our study is based on 33 diverse tropical maize inbred lines (Table 1). These were selected by INRA Montpellier from the maize inbred line reference set of the Generation Challenge Program, based on genetic maker information to build a most representative subset.

Experimental setup and growing conditions

During the 2008 summer season (May-July), the 33 inbred lines were grown in the greenhouse up to three different development stages, i.e., full development of the second leaf (2-leaf), fourth leaf (4-leaf), and sixth leaf (6-leaf). We applied a split-plot design with harvest time (3 levels) as main-plot treatment. Within each main-plot, inbred lines (33 levels) were assigned to sub-plots that were arranged in incomplete blocks according to a 7-by-5 alpha-design (Patterson and Williams 1976). Each sub-plot consisted of one plant grown in a growth column consisting of a PVC tube filled with
Table 1 List of tropical maize inbred lines examined within the study

\begin{tabular}{llllll}
\hline Inbred line & $\begin{array}{l}\text { Grown } \\
\text { in field }\end{array}$ & Inbred line & $\begin{array}{l}\text { Grown } \\
\text { in field }\end{array}$ \\
\hline 1 & CML247 & Yes & 18 & CZL04006 & \\
2 & CML254 & Yes & 19 & CZL0617 & \\
3 & CML287 & Yes & 20 & CZL071 & \\
4 & CML312 & Yes & 21 & DTPWC9-F104 & Yes \\
5 & CML333 & Yes & 22 & DTPWC9-F115 & Yes \\
6 & CML339 & & 23 & DTPWC9-F31 & Yes \\
7 & CML340 & Yes & 24 & DTPYC9-F46 & Yes \\
8 & CML341 & Yes & 25 & DTPYC9-F74 & Yes \\
9 & CML344 & Yes & 26 & H16 & \\
10 & CML360 & & 27 & K64R & \\
11 & CML389 & & 28 & KU13 & Yes \\
12 & CML440 & Yes & 29 & LPSC7-F103 & Yes \\
13 & CML444 & Yes & 30 & LPSC7-F64 & Yes \\
14 & CML69 & Yes & 31 & LPSC7-F71 & Yes \\
15 & CML91 & Yes & 32 & LPSC7-F86 & Yes \\
16 & CMLP1 & & 33 & SCMALAWI & \\
17 & CMLP2 & & & & \\
\hline
\end{tabular}

soil substrate (see detailed description below). Each main-plot consisted of a greenhouse cart loaded with 35 growth columns (33 genotypes +2 unplanted control growth columns). The experiment was conducted with three replications that were performed consecutively over time. Within one replication, plants were sown at the same time into the $3 \times 33$ growth columns (sub-plots) and the main plots were destructively harvested when the plants in average reached the designated growth stage.

The growth columns had a diameter of $10.5 \mathrm{~cm}$ and a height of 40, 60, and $80 \mathrm{~cm}$ for plants to be harvested at the 2-leaf, 4-leaf, and 6-leaf stage, respectively. The stage-dependent height of the columns has been chosen based on earlier experiments to avoid that more than $2 \%$ of the roots reached the lowest section. This had two reasons: i) to avoid a non-normal distribution of the roots due to an accumulation or roots at the bottom of the column and ii) to avoid a possible feedback signal of these roots causing an overall change of the root distribution. The soil substrate consisted of a $3.5: 1 \mathrm{w} / \mathrm{w}$ mixture of quartz sand $(0.08-0.20 \mathrm{~mm}$ particle diameter) and a porous baked clay granulate of $0.5-4.0 \mathrm{~mm}$ particle diameter (SERAMIS, Mars Inc., McLean, VA, USA). The baked clay was added to increase the water 
holding capacity of the substrate. Before filling the growth columns, the substrate was moistened with a $0.23 \%(\mathrm{v} / \mathrm{v})$ Wuxal nutrient solution (Aglukon Spezialdünger GmbH, Düsseldorf, Germany: $16 \mathrm{mM} \mathrm{N} ; 1 \mathrm{mM} \mathrm{P}_{2} \mathrm{O}_{5} ; 2 \mathrm{mM} \mathrm{K} \mathrm{O}_{2} ; 7.8 \mu \mathrm{M} \mathrm{Fe}$; $6.7 \mu \mathrm{M} \mathrm{Mn} ; 21.3 \mu \mathrm{M}$ B; $2.9 \mu \mathrm{M} \mathrm{Cu} ; 2.2 \mu \mathrm{M} \mathrm{Zn}$ $1.1 \mu \mathrm{M} \mathrm{Mo})$ to its maximum water holding capacity (approx. $35 \%$ of dry weight of the substrate). To enable sufficient drainage and avoid water logging in the lower parts, the caps at the bottom of each column were punched with holes of approx. $4 \mathrm{~mm}$ diameter.

Seeds were surface-sterilized in a $2.5 \% \mathrm{NaOCl}$ solution and pre-germinated for 3 days at $27^{\circ} \mathrm{C}$ on moistened blotting paper. Two germinated seeds were placed in each growth column at a depth of $2.5 \mathrm{~cm}$ and thinned to one plant per growth column 4 to 5 days after germination. The growth columns were covered with an aluminum foil punched at the seedling position and watered twice a week with a $0.23 \%(\mathrm{v} / \mathrm{v})$ Wuxal nutrient solution to maintain the maximum water holding capacity. To determine the amount of nutrient solution required, the evapotranspiration since the last watering was determined by weighing three randomly chosen growth columns per main-plot.

\section{Shoot and root measurements at harvest}

Plants were harvested 10-11, 18, and 26-28 days after sowing for the 2-leaf, 4-leaf, and 6-leaf stage, respectively. At harvest, the shoots were cut at surface level and the growth columns were immediately transferred to a cooling chamber at $4{ }^{\circ} \mathrm{C}$ to minimize respiration during storage (3-5 days) until further processing. Leaf area of the harvested shoots $\left(\mathrm{A}_{\mathrm{Lf}}\right)$ was measured with a leaf area meter (LI-3000A, LI-COR Inc, Lincoln, NE, USA).

To determine root traits, the growth columns were opened longitudinally (two half pipes) and subdivided into eight different depth segments that were 5, 7.5, and $10 \mathrm{~cm}$ long for the 2-leaf, 4-leaf, and 6-leaf stage, respectively. Roots were extracted from the soil substrate for each depth segment by rinsing under running tap water. At the base of the stem, the total number of crown roots $\left(\mathrm{N}_{\mathrm{Cr}}\right)$ was counted. The gravimetric setpoint angle $\left(\mathrm{Ang}_{\mathrm{Cr}}\right)$ and diameter $\left(\mathrm{D}_{\mathrm{Cr}}\right)$ of crown roots were measured on plants harvested at the 4-leaf and 6leaf stage for each node number separately. Ang $_{\text {Cr }}$ was measured using a triangle ruler whereby vertical growth at emergence was recorded as $0^{\circ}$, horizontal growth as $90^{\circ} . \mathrm{D}_{\mathrm{Cr}}$ was measured $2 \mathrm{~cm}$ apical to the root emerging point using a digital caliber. Washed root samples of single depth segments were stored in plastic bags at $4{ }^{\circ} \mathrm{C}$ for further processing.

\section{Determination of root length}

Total root length was determined according to the methylene-blue adsorption method described by Sattelmacher et al. (1983). For this purpose, root samples of each depth segment were rinsed with distilled water and stained for $60 \mathrm{~s}$ in a methylene blue solution (74.7 mg/l), followed by rinsing off the surplus solution with distilled water. After staining, the root samples were transferred to a $0.1 \mathrm{M} \mathrm{CaCl}_{2}$ solution for $60 \mathrm{~s}$ to exchange the methylene blue absorbed by the roots. The amount of $\mathrm{CaCl}_{2}$ solution was individually adjusted to the size of the root sample and ranged from $5 \mathrm{ml}$ for smallest to $75 \mathrm{ml}$ for largest root samples. Two aliquots (200 $\mu$ l) of each sample of the $\mathrm{CaCl}_{2}$ solutions containing the resolved methylene blue were transferred to $96-$ well plates, and extinctions were measured at $650 \mathrm{~nm}$ with a photometer (ELISA Reader MR 5000, Dynatech, Burlington, VT, USA). All extinctions were measured relatively to a $0.1 \mathrm{M} \mathrm{CaCl}_{2}$ blank. Since the amount of $\mathrm{CaCl}_{2}$ solution used for resolving methylene blue from the roots varied from sample to sample, the obtained relative extinctions were all standardized to a $50 \mathrm{ml}$ $\mathrm{CaCl}_{2}$ solution (Ext).

To translate the measured Ext values into real root length, all root samples from six selected inbred lines were scanned and analyzed for root length using an image processing software (details see below). For this purpose, root samples were collected after applying the staining approach, spread in a plastic tray filled with water and scanned with a scanner equipped with top light (Epson, Expression 1640 XL, Epson America, Inc., USA) at $600 \mathrm{dpi}$ and 8 bit color resolution. To enhance the contrast between roots and background, the following procedures were applied to all images using Photoshop 7.0 (Adobe Systems Inc., San Jose, CA, USA); application of a median filter with a radius of 2 pixels to remove image noise and application of a tonal threshold value of 220 to reduce the 8 bit grayscale images to 1 bit monochrome images. All images were subsequently analyzed with WinRHIZO (Version 2003b, Regent Instruments, Montreal, QC, Canada) to measure root length. The debris removal filter was set to remove objects with an area smaller than $0.005 \mathrm{~cm}^{2}$ and 
a length/width ratio lower than 5 . The total root length $\left(\mathrm{L}_{\mathrm{Rt}}\right)$ for each depth segment as determined by image processing was retrieved from the WinRHIZO output.

To relate measured Ext to $\mathrm{L}_{\mathrm{Rt}}$ as determined by image acquisition, the following model was employed:

$\ln \left(\mathrm{L}_{\mathrm{Rt}}\right) \sim \ln (\mathrm{Ext})+\ln (\mathrm{Ext}) \times \mathrm{V}_{\mathrm{CaCl} 2}$

where $\ln ()$ denotes the natural logarithm, $\mathrm{L}_{\mathrm{Rt}}$ the root length determined by image processing, Ext the extinction standardized to $50 \mathrm{ml} \mathrm{CaCl}_{2}$ solution, and $\mathrm{V}_{\mathrm{CaCl} 2}$ the amount of $\mathrm{CaCl}_{2}$ solution used for exchanging root absorbed methylene blue. Additionally to Ext, we also employed root dry weight $\left(\mathrm{DW}_{\mathrm{Rt}}\right)$ of the samples to predict their root length according to the following equation:

$\ln \left(\mathrm{L}_{\mathrm{Rt}}\right) \sim \ln \left(\mathrm{DW} \mathrm{Rt}_{\mathrm{t}}\right.$

where $\ln \left(\mathrm{DW}_{\mathrm{Rt}}\right)$ denotes the natural logarithm of $\mathrm{DW}_{\mathrm{Rt}}$.

To evaluate performance of Eqs. [1] and [2] to predict $\ln \left(\mathrm{L}_{\mathrm{Rt}}\right)$, a leave-one-out cross validation (Arlot and Celisse 2010) was performed, which yielded a coefficient of determination $\left(\mathrm{R}^{2}\right)$ of 0.90 for both equations (Fig. 1). Equation [1] was then used to predict $\mathrm{L}_{\mathrm{Rt}}$ in the complete experiment using the following final calibration model:

$L_{R t}=\exp \left(8.338+1.203 \times \ln (E x t)-0.0059 \times \ln (E x t) \times V_{C a C l 2}\right)$

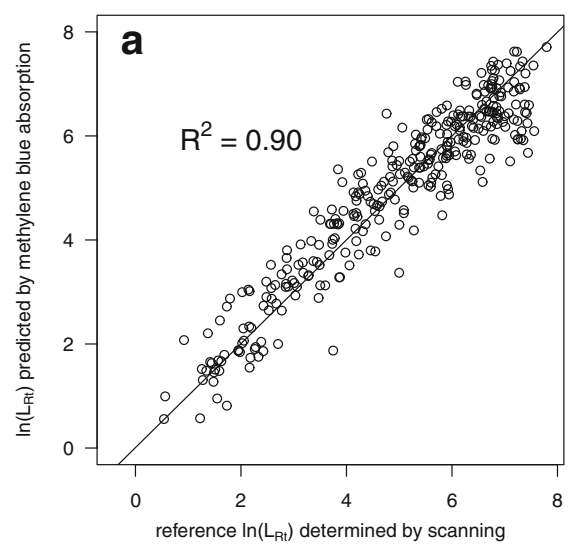

Fig. 1 Correlation between root length $\left(\mathrm{L}_{\mathrm{Rt}}\right)$ as determined by scanning and as predicted by leave-one-out cross validation (both transformed by natural logarithm) upon a the methylene blue
Calculation of root distribution parameters

Distribution curves of standardized cumulative length of the roots $\left(\mathrm{SCL}_{\mathrm{Rt}}\right)$ were produced for each plot (example given in Fig. 2), with $\mathrm{SCL}_{\mathrm{Rt}}$ in a certain depth segment being calculated as:

$S C L_{R t, i}=\sum_{k=1}^{i} L_{R t, k} / \sum_{k=1}^{8} L_{R t, k}$

where $S C L_{R t, i}$ is the standardized cumulative root length in depth segment $\mathrm{i}$ (with $i=1$ being the uppermost and $i=8$ being the deepest segment) and $L_{R t, k}$ is the root length in segment $\mathrm{k}$ determined following Eq. [3]. Between each two adjacent points, the $\mathrm{SCL}_{\mathrm{Rt}}$ curves were interpolated by linear regression (Fig. 2). The soil depth above which $95 \%$ of the total root system in terms of root length is located $\left(\mathrm{D}_{95}\right)$ was then determined as an indicator of rooting depth as illustrated in Fig. 2. The proportion of deep roots to total roots (DR) was determined using two types of threshold to separate between deep and shallow roots: a flexible threshold relative to rooting depth determined as half the measured $\mathrm{D}_{95}$ (DR) and a fix threshold determined as half the column length $\left(\mathrm{DR}_{\mathrm{fix}}\right)$.

Field data

A subset of 22 inbred lines (Table 1) was grown among other genotypes with three replicates during the

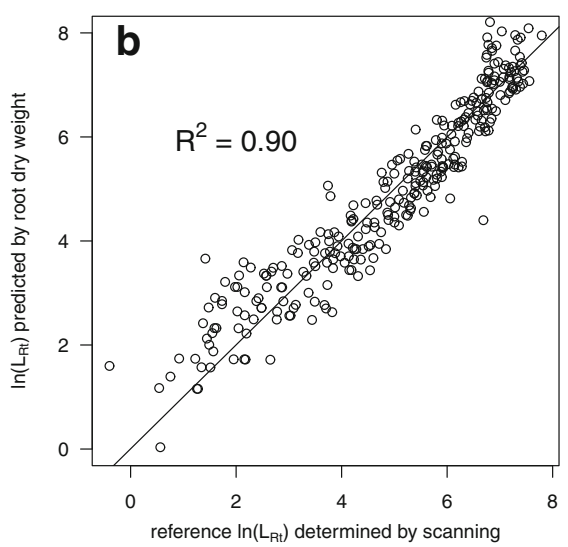

absorption and $\mathbf{b}$ root dry weight. Coefficients of determination $\left(\mathrm{R}^{2}\right)$ given in the plot were determined from cross validation 
Fig. 2 Calculation of rootdistribution parameters $D_{95}$ and DR, graphically illustrated on the standardized cumulative root length $\left(\mathrm{SCL}_{\mathrm{Rt}}\right)$ curve of a growth column harvested at 6-leaf stage. Arrows indicate the calculation of $\mathrm{D}_{95}$ and, using half of $\mathrm{D}_{95}\left(\mathrm{D}_{95} / 2\right)$ as a threshold, determination of deep (a) and shallow (b) roots, which are needed for calculation of the deep root ratio (DR)

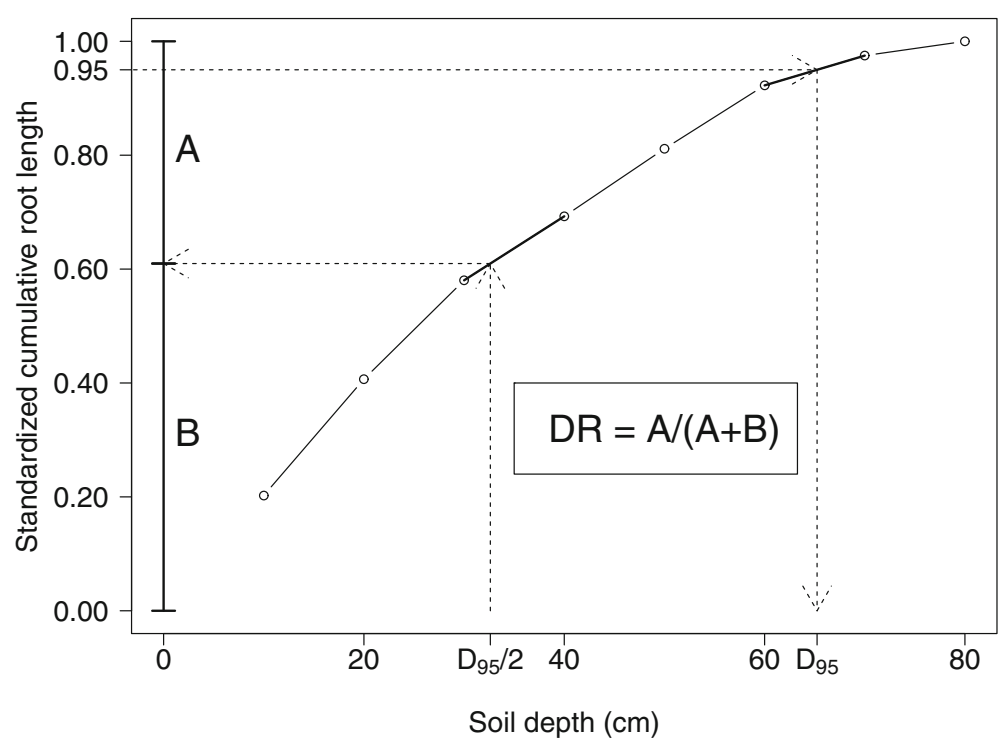

2008/2009 winter season at the experimental station of the International Wheat and Maize Improvement Center (CIMMYT) in Tlaltizapan (Morelos, México; $18^{\circ} 41^{\prime} \mathrm{N}$, $99^{\circ} 10^{\prime} \mathrm{W}, 940 \mathrm{~m}$ a.s.l.). Inbred lines were planted on the 4th of December 2008 in single row plots at a density of 6.6 plants per $\mathrm{m}^{2}$. Plots were harvested on the 7 th of May 2009. The soil at the station is a black vertisol developed from calcareous subsoil with a $\mathrm{pH}$ of 8.5. For the experiments, two different treatments were applied: full irrigation (well watered) and withholding irrigation 2 weeks before flowering (drought stress). During flowering, dates of anthesis and silking were recorded as time when $50 \%$ of plants within a plot were shedding pollen or growing silks, respectively. The anthesis silking interval (ASI) was calculated as the difference in days between silking and anthesis. Grain yield per unit area (GY) was calculated as the product of the planting density with the average yield per plant in a plot. Leaf chlorophyll content (SPAD), measured by a SPAD-502 instrument (Konica Minolta Sensing, Inc., Sakai, Osaka, Japan), was determined 2 weeks after flowering. Leaf rolling was determined under drought stressed conditions 1 week after flowering. Genotypic means for each trait were calculated separately for the two treatments.

\section{Statistical analysis}

All traits determined in the greenhouse were analyzed within a mixed model framework. Traits related to root distribution and the shoot $\left(\mathrm{L}_{\mathrm{Rt}}, \mathrm{D}_{95}, \mathrm{DR}, \mathrm{N}_{\mathrm{Cr}}\right.$ and $\left.\mathrm{A}_{\mathrm{Lf}}\right)$ were analyzed using the following model

$y_{i j n k}=\mu+g_{i}+t_{j}+(g t)_{i j}+r_{n}+C_{n j}+B_{n j k}+\varepsilon_{i j n k}$

where $\mu$ denotes the overall mean, $g_{i}$ is the effect of the $\mathrm{i}^{\text {th }}$ genotype, $t_{j}$ (covariate) is the number of days until harvest, $(g t)_{i j}$ is the interaction between the $\mathrm{i}^{\text {th }}$ genotype and the days until harvest, $r_{n}$ is the $\mathrm{n}^{\text {th }}$ replication, $C_{n j}$ defines the whole plot, $B_{n j k}$ defines the incomplete blocks and $\varepsilon_{i j n k}$ is the residual error. All effects except the random terms $C_{n j}, B_{n j k}$, and $\varepsilon_{i j n k}$ were treated as fixed. To estimate genotypic variance at 6-leaf stage, the following reduced model of Eq. [5]

$y_{i n k}=\mu+g_{i}+r_{n}+B_{n k}+\varepsilon_{i n k}$

was employed only on data from the 6-leaf stage, taking all effects except $r_{n}$ as random. Heritability $\left(h^{2}\right)$ was then calculated for each trait as $\mathrm{h}^{2}=\sigma_{\mathrm{g}}^{2} /\left(\sigma_{\mathrm{g}}^{2}+\sigma_{\varepsilon}^{2} / \mathrm{R}\right)$ with $\sigma_{\mathrm{g}}^{2}$ and $\sigma_{\varepsilon}^{2}$ being the genotypic and residual variance, respectively, and $R=3$ being the number of replications.

Development of crown root traits $\left(\mathrm{D}_{\mathrm{Cr}}\right.$ and $\left.\mathrm{Ang}_{\mathrm{Cr}}\right)$, which were only measured at the 4-leaf and 6-leaf stage, was analyzed as a function of the node number using the following equation

$y_{i j n k}=\mu+g_{i}+a_{j}+(g a)_{i j}+r_{n}+B_{n k}+\varepsilon_{i j n k}$ 
where $a_{j}$ (covariate) is the node number and $(g a)_{i j}$ is the interaction between the $i^{\text {th }}$ genotype and node number. All effects except the random terms $B_{n k}$ and $\varepsilon_{i j n k}$ were treated as fixed. Due to observation on the same experimental unit (plant in growth column), residuals of the different nodes were modeled to be correlated following an autoregressive (AR1) correlation model. Residuals in Eqs. [5-7] were inspected for normality and homoscedasticity and, if necessary, variables were subjected to suitable transformations (ln). Genotypic means for intercepts at 6-leaf stage (i.e. genotypic performance at 6leaf stage) and development rates were predicted for each trait from the estimated effects.

\section{Correlations}

As a further parameter, the leaf area-rooting depth relation $\left(\mathrm{A}_{\mathrm{Lf}}-\mathrm{D}_{95}\right)$ was calculated by regressing genotypic means of $\mathrm{A}_{\mathrm{Lf}}$ on $\mathrm{D}_{95}$ (Fig. 3) and taking the vertical distance of each genotypic observation to the geometric-mean-regression line (regression residuals). Thus, genotypes with positive $\mathrm{A}_{\mathrm{Lf}}-\mathrm{D}_{95}$ show large leaf area in relation to their rooting depth and vice versa. Phenotypic correlation coefficients $\left(r_{p}\right)$ among traits were calculated as Pearsons's correlations coefficients of genotypic means, being based on 33 (among traits measured in growth columns) or the 22 overlapping genotypic means (between field and growth column traits). All calculations were performed within the R- environment (R Core Development Team 2009), using the package ASReml (Gilmour et al. 2006) for mixed modeling.

\section{Results}

Means and variation

The analysis of development of root distributional (see ESM Fig. 1 for the root distribution profiles) and shoot traits with time required a logarithmic transformation for $\mathrm{L}_{\mathrm{Rt}}$ and $\mathrm{A}_{\mathrm{Lf}}$, indicating that these two traits follow an exponential growth pattern. Positive mean and range of genotype specific development rates for all traits indicated that root system size, depth of the majority of root as indicated by $\mathrm{D}_{95}$ and leaf area increased with time (Table 2). Analysis of variance revealed a highly significant $(P<0.001)$ effect of genotype for all traits, meaning that inbred lines showed different intercepts in their development curves (i.e., differed in their performance at a given time). Further, the highly significant $(P<0.001)$ effect of time showed that all traits changed significantly with time. However, genotypic differences in the development rate (i.e. genotype-by-time interactions) were only significant for $\mathrm{D}_{95}(P<0.01)$ and $\mathrm{N}_{\mathrm{Cr}}(P<0.001)$ (see ESM Fig. 2a, b for examples).
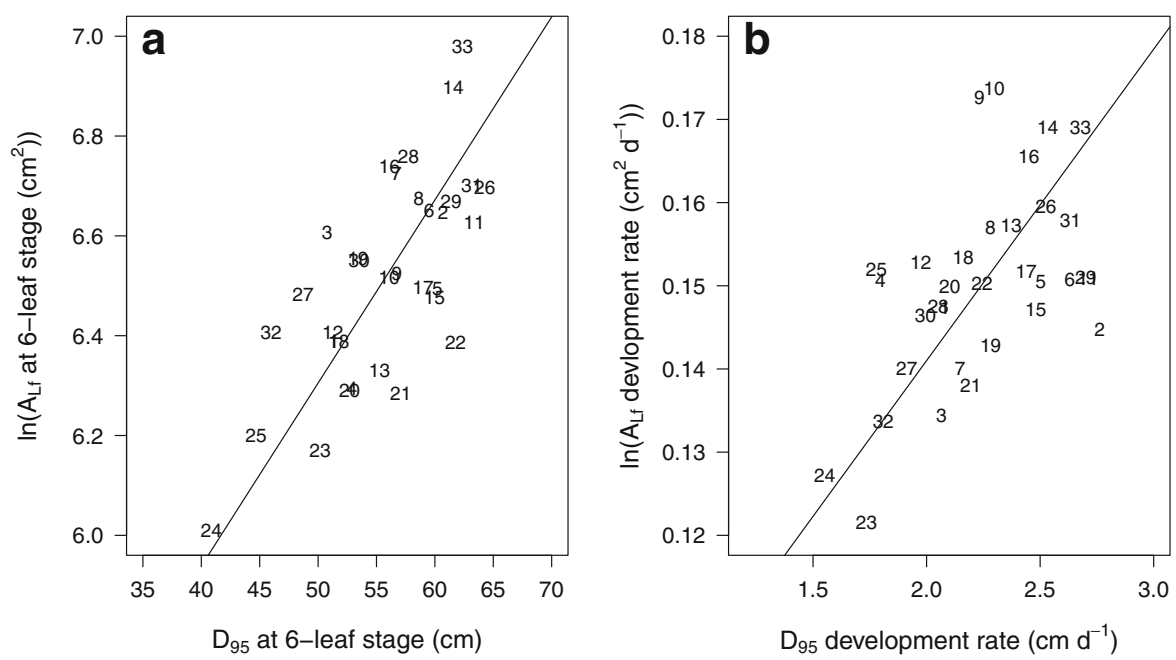

Fig. 3 Correlation between rooting depth $\left(D_{95}\right)$ and total leaf area $\left(A_{L f}\right)$ for a values as measured at the 6-leaf stage, and $\mathbf{b}$ the development rates between 2- and 6-leaf stage. Numbers give the 33 inbred lines following Table 1, solid lines indicate the geometric mean regression 
Table 2 ANOVA table and (in the lower part of the table) range, mean, Tukey honest significant difference (HSD) and heritability $\left(\mathrm{h}^{2}\right)$ of genotypic means for measurements at the 6-leaf stage and development rates between 2- and 6-leaf stage for the traits total root length $\left(\mathrm{L}_{\mathrm{Rt}}\right)$, rooting depth $\left(\mathrm{D}_{95}\right)$, deep root ratio $(\mathrm{DR})$, total leaf area $\left(\mathrm{A}_{\mathrm{Lf}}\right)$, and crown root number $\left(\mathrm{N}_{\mathrm{Cr}}\right)$

\begin{tabular}{|c|c|c|c|c|c|c|}
\hline & df & $\begin{array}{l}\ln \left(\mathrm{L}_{\mathrm{Rt}}\right) \\
\ln (\mathrm{cm})\end{array}$ & $\begin{array}{l}\mathrm{D}_{95} \\
(\mathrm{~cm})\end{array}$ & $\begin{array}{l}\text { DR } \\
\%\end{array}$ & $\begin{array}{l}\ln \left(\mathrm{A}_{\mathrm{Lf}}\right) \\
\ln \left(\mathrm{cm}^{2}\right)\end{array}$ & $\begin{array}{l}\mathrm{N}_{\mathrm{Cr}} \\
\#\end{array}$ \\
\hline Intercept & 1 & $* * *$ & $* * *$ & $* * *$ & $* * *$ & $* * *$ \\
\hline Inbred line & 32 & $* * *$ & $* * *$ & $* * *$ & $* * *$ & $* * *$ \\
\hline Time & 1 & $* * *$ & $* * *$ & $* * *$ & $* * *$ & $* * *$ \\
\hline Inbred line:Time & 32 & - & $* *$ & - & - & $* * *$ \\
\hline \multicolumn{7}{|c|}{ Genotype specific intercept at 6-leaf stage } \\
\hline Range & & $7.93-8.83$ & $40.8-64.2$ & $30-50$ & $6.01-6.98$ & $8.7-19.3$ \\
\hline Mean & & 8.46 & 55.75 & 40.00 & 6.52 & 12.1 \\
\hline HSD & & 1.39 & 15.71 & 16.80 & 1.00 & 4.8 \\
\hline $\mathrm{h}^{2}$ & & 0.48 & 0.62 & 0.27 & 0.40 & 0.78 \\
\hline \multicolumn{7}{|c|}{ Genotype specific development rate } \\
\hline Range & & $0.079-0.143$ & $1.56-2.77$ & $0.0024-0.015$ & $0.123-0.174$ & $0.21-0.74$ \\
\hline Mean & & 0.117 & 2.25 & 0.0084 & 0.150 & 0.44 \\
\hline HSD & & 0.098 & 1.343 & 0.014 & 0.067 & 0.4 \\
\hline
\end{tabular}

$* *, * * *$ significant at the 0.01 , and 0.001 probability level, respectively

Among crown root traits, the logarithmic transformation required for $\mathrm{D}_{\mathrm{Cr}}$ indicated an exponential increase with ascending node number (Table 3). The range of genotype specific development rates for

Table 3 ANOVA table and (in the lower part of the table) range, mean and Tukey honest significant difference (HSD) of genotypic means for measurements at the 3 rd node number and development rates with node number for the traits crown root diameter $\left(\mathrm{D}_{\mathrm{Cr}}\right)$ and crown root angle $\left(\mathrm{Ang}_{\mathrm{Cr}}\right)$

\begin{tabular}{lccl}
\hline & df & $\begin{array}{l}\ln \left(\mathrm{D}_{\mathrm{Cr}}\right) \\
\ln (\mathrm{mm})\end{array}$ & $\begin{array}{l}\mathrm{Ang}_{\mathrm{Cr}} \\
\left({ }^{\circ}\right)\end{array}$ \\
\hline Intercept & 1 & $* * *$ & $* * *$ \\
Inbred line & 32 & $* * *$ & $* * *$ \\
Node & 1 & $* * *$ & $* * *$ \\
Inbred line:Node & 32 & $* * *$ & - \\
Genotype specific intercept at node 3 & \\
$\quad$ & $0.031-0.856$ & $26.1-60.6$ \\
$\quad$ Range & 0.391 & 43.0 \\
$\quad$ Mean & 0.344 & 23.8 \\
Genotype specific development rate & \\
Range & $0.246-0.526$ & $-8.83-1.36$ \\
Mean & 0.362 & -3.89 \\
HSD & 0.205 & 14.55 \\
\hline
\end{tabular}

*** significant at the 0.001 probability level
Ang $_{\mathrm{Cr}}\left(-8.83-1.36^{\circ}\right)$ indicated that crown roots of most genotypes grew steeper with increasing node number. Contrary, $\mathrm{D}_{\mathrm{Cr}}$ of all genotypes increased with ascending node number by $1.4 \mathrm{~mm}$ per node on average. The analysis of variance for the development of $\mathrm{D}_{\mathrm{Cr}}$ and $\mathrm{Ang}_{\mathrm{Cr}}$ with node number also indicated highly significant $(P<0.001)$ effects of genotype and node number, meaning that genotypes differed for their intercept and that both traits changed with ascending node number. Significant genotypic differences in the development with node number (i.e. genotype-by-node interactions) were observed for $\mathrm{D}_{\mathrm{Cr}}$ (see ESM Fig. $2 \mathrm{c}$ for example), but not for $\mathrm{Ang}_{\mathrm{Cr}}$. Means and ranking of all genotypes can be seen in ESM Table 1 for root distributional and shoot traits and in ESM Table 2 for crown root traits.

\section{Correlations among traits}

Based on values measured at the 6-leaf stage, $\mathrm{L}_{\mathrm{Rt}}, \mathrm{D}_{95}$ and $\mathrm{DR}_{\text {fix }}$ were positively correlated, but none of these traits showed an association with DR (Table 4, upper triangular part). $\mathrm{A}_{\mathrm{Lf}}$ showed moderate, positive correlations with $\mathrm{D}_{95}$ and $\mathrm{L}_{\mathrm{Rt}}$. The empirically derived relationship between $\mathrm{D}_{95}$ and $\mathrm{L}_{\mathrm{Rt}}$ (Fig. 3) can be used to identify inbred lines having a more or less deep reaching root system relative to shoot size, whereby inbred lines 
Table 4 Correlations $(n=33)$ among root and shoot parameters based on values measured at the 6-leaf stage (upper triangle) and based on the development rates between 2- and 6-leaf stage (lower triangle, only given between traits which showed significant genotypic differences in development rate). Traits are total root length $\left(\mathrm{L}_{\mathrm{Rt}}\right)$, rooting depth $\left(\mathrm{D}_{95}\right)$, deep root ratios based on flexible (DR) and fix $\left(\mathrm{DR}_{\text {fix }}\right)$ threshold, total leaf area $\left(\mathrm{A}_{\mathrm{Lf}}\right)$, leaf area - rooting depth relation $\left(\mathrm{A}_{\mathrm{Lf}}-\mathrm{D}_{95}\right)$ and crown root number $\left(\mathrm{N}_{\mathrm{Cr}}\right)$

\begin{tabular}{|c|c|c|c|c|c|c|c|}
\hline & $\ln \left(L_{\mathrm{R}}\right)$ & $\mathrm{D}_{95}$ & DR & $\mathrm{DR}_{\text {fix }}$ & $\ln \left(A_{L f}\right)$ & $\mathrm{A}_{\mathrm{Lf}}-\mathrm{D}_{95}$ & $\mathrm{~N}_{\mathrm{Cr}}$ \\
\hline $\ln \left(\mathrm{L}_{\mathrm{Rt}}\right)$ & & $0.62^{\mathrm{b}}$ & 0.33 & $0.63^{\mathrm{b}}$ & $0.70^{\mathrm{b}}$ & 0.11 & 0.22 \\
\hline $\mathrm{D}_{95}$ & & & 0.01 & $0.92^{\mathrm{b}}$ & $0.71^{\mathrm{b}}$ & $-0.38^{\mathrm{a}}$ & 0.22 \\
\hline DR & & & & 0.07 & 0.24 & 0.30 & 0.23 \\
\hline $\mathrm{DR}_{\mathrm{fix}}$ & & & & & $0.60^{\mathrm{b}}$ & $-0.41^{\mathrm{a}}$ & 0.26 \\
\hline $\ln \left(A_{L f}\right)$ & & & & & & $0.38^{\mathrm{a}}$ & 0.24 \\
\hline$A_{L f}-D_{95}$ & & & & & & & 0.03 \\
\hline $\mathrm{N}_{\mathrm{Cr}}$ & & 0.22 & & & & & \\
\hline
\end{tabular}

a,b significant at the $0.05,0.01$ probability level, respectively

deviating negatively from the regression line can be characterized as relatively deep rooting (negative $A_{L f^{-}}$ $\mathrm{D}_{95}$ value). The allometric parameter $\mathrm{A}_{\mathrm{Lf}}-\mathrm{D}_{95}$ showed a moderate correlation $\left(\left|r_{p}\right|=0.38\right)$ with its first $\left(\mathrm{A}_{\mathrm{Lf}}\right)$ and second $\left(\mathrm{D}_{95}\right)$ components, but with no other trait determined in the greenhouse. Between the two traits that showed significant genotypic differences in the development rate between the 2- and 6-leaf stage $\left(\mathrm{N}_{\mathrm{Cr}}, \mathrm{D}_{95}\right)$, the correlation based on development rate was not significant (Table 4, lower triangular part).
Phenotypic correlation coefficients between greenhouse and field performance were low, not exceeding 0.50 (Table 5). Based on observations at the 6-leaf stage, GY under drought tended to be negatively correlated with most growth column parameters, (significant for $\ln \left(\mathrm{L}_{\mathrm{Rt}}\right)$ and $\ln \left(\mathrm{A}_{\mathrm{Lf}}\right)$ ). Furthermore, high $\mathrm{A}_{\mathrm{Lf}}-\mathrm{D}_{95}$ (i.e. large leaf area in relation to rooting depth) showed a negative association with SPAD under drought. Genotypes progressing faster in their number of crown roots $\left(\mathrm{N}_{\mathrm{Cr}}\right)$ showed a negative association with yield under drought.

\section{Discussion}

Measuring rooting depth

As roots were harvested per column section, the rooting depth could only be given with the precision of the section limits e.g. in $10 \mathrm{~cm}$ intervals for the $80-\mathrm{cm}$ columns. To gain precision, we decided to use the $\mathrm{D}_{95}$ method described by Schenk and Jackson (2002) to estimate rooting depth and used linear interpolation between the depth segments to determine $\mathrm{D}_{95}$. Generally, no or only few roots were found in the lowest depth segment, and the precondition for a correct calculation of $\mathrm{D}_{95}$, i.e. less than $5 \%$ roots in the lowest depth segment (see genotypic means of actual values at the 6-leaf stage in ESM Table 1), was only harmed in one
Table 5 Correlations $(n=22)$ between parameters measured in the greenhouse and in the field a significant at the 0.05 probability level

\begin{tabular}{|c|c|c|c|c|c|c|c|}
\hline & \multicolumn{4}{|c|}{ Drought stress } & \multicolumn{3}{|c|}{ Well watered } \\
\hline & GY & ASI & SPAD & LR & GY & ASI & SPAD \\
\hline \multicolumn{8}{|c|}{ Intercept at 6-leaf stage or node 3} \\
\hline $\ln \left(\mathrm{L}_{\mathrm{Rt}}\right)$ & $-0.46^{\mathrm{a}}$ & 0.21 & -0.34 & 0.17 & -0.11 & 0.18 & -0.38 \\
\hline $\mathrm{D}_{95}$ & -0.29 & 0.16 & 0.01 & 0.16 & -0.06 & 0.12 & -0.26 \\
\hline DR & -0.31 & -0.01 & -0.26 & 0.14 & 0.24 & -0.25 & 0.04 \\
\hline $\ln \left(\mathrm{A}_{\mathrm{Lf}}\right)$ & $-0.50^{\mathrm{a}}$ & 0.16 & -0.35 & 0.24 & -0.04 & 0.10 & $-0.47^{\mathrm{a}}$ \\
\hline $\mathrm{A}_{\mathrm{Lf}}-\mathrm{D}_{95}$ & -0.28 & 0.00 & $-0.46^{\mathrm{a}}$ & 0.10 & 0.03 & -0.02 & -0.27 \\
\hline $\mathrm{N}_{\mathrm{Cr}}$ & -0.36 & -0.04 & -0.36 & 0.12 & -0.24 & $0.44^{\mathrm{a}}$ & -0.24 \\
\hline $\ln \left(\mathrm{D}_{\mathrm{Cr}}\right)$ & -0.01 & 0.34 & -0.01 & 0.18 & 0.08 & -0.02 & -0.08 \\
\hline $\operatorname{Ang}_{\mathrm{Cr}}$ & 0.24 & -0.33 & -0.25 & -0.01 & 0.13 & -0.17 & -0.11 \\
\hline \multicolumn{8}{|c|}{ Development rate per day or node } \\
\hline $\mathrm{D}_{95}$ & -0.32 & 0.07 & -0.07 & 0.15 & -0.05 & -0.08 & -0.22 \\
\hline $\mathrm{N}_{\mathrm{Cr}}$ & $-0.44^{\mathrm{a}}$ & 0.00 & -0.33 & 0.11 & -0.19 & 0.31 & -0.28 \\
\hline $\ln \left(\mathrm{D}_{\mathrm{Cr}}\right)$ & 0.17 & 0.15 & -0.10 & 0.20 & 0.01 & -0.14 & -0.03 \\
\hline
\end{tabular}


plot. Linear interpolaton proved to be more robust to summarize the results of differently shaped curves (compare ESM Figure 1) of the vertical distributions as compart to smoothing splines used by Hund et al. (2009a). It may be criticised that $\mathrm{D}_{95}$ is not an appropriate measure to characterize genotypes with regard to their potential for water extraction from deep soil strata. For example, one single, deep root making in total less than $95 \%$ of the root system may be enough to tab water. Accordingly, its contribution to rooting depth would not be adequately represented by $\mathrm{D}_{95}$. However, maize has a fibrous root system with many axile roots simultaneously growing into the soil profile. Therefore, we assume that $\mathrm{D}_{95}$ and the absolute depth reached by the deepest root should be closely correlated.

Suitable methods to measure root length

The staining method with methylene blue as described by Sattelmacher et al. (1983) was suitable to determine root length in our study. Compared to the scanning approach, time requirements (from the washed roots until availability of a data point for root length) were slightly higher for small root samples derived from plants at the 2-leaf stage, but reduced up to $50 \%$ for larger root samples derived at the 4- and 6-leaf stage (data not shown). However, being able to predict $\mathrm{L}_{\mathrm{Rt}}$ with a similar precision by just taking $\mathrm{DW}_{\mathrm{Rt}}$ (Fig. 1b) does not justify the additional time required for staining.

Roots vary in their diameter (e.g. thick axile vs. thin lateral roots) and therefore also for their surface area-toweight ratio. Absorption of methylene blue is directly linked to the root surface (and length) and would be expected to be a better predictor for root length than root dry weight. Different nuisance factors may cause small errors accumulating during the complex procedure (i.e. staining, exchange of absorbed methylene blue, extinction measurements). To improve the prediction of $\mathrm{L}_{\mathrm{Rt}}$ based on the absorption of the dye, we included controllable factors (e.g. volume of $\mathrm{CaCl}_{2}$ solution used to resolve adsorbed dye) into Eq. [1] to account for their effects. However, non-controllable nuisance factors seemed to outweigh the staining method's benefit of being directly linked to root surface area. Hence, if only a proxy measure of root length is required (e.g. when screening large populations), simple weighing of roots should be preferred over staining. If more detailed aspects of the root system are to be examined, scanning of roots followed by image processing should be preferred because roots of different diameter classes can be distinguished.

Strong genotypic control of root traits related to plant vigor

We found significant genotypic variation for all root traits at the 6-leaf stage and, in some cases, also for their development with time $\left(\mathrm{D}_{95}, \mathrm{~N}_{\mathrm{Cr}}\right)$, or with node number $\left(D_{C r}\right)$, although the number of replications (three) per inbred line was comparably low. The final architecture of a root system in the soil is a function of its dynamic interaction with chemical, biological and physical factors (Lynch 1995). Taking into account the very heterogeneous and dynamic soil environments under field conditions, large genotype-by-environment interactions can be expected and heritability of a "deep rooting" trait would be rather low (Richards et al. 2000). Interestingly, estimates of heritability determined at the 6-leaf stage for root length (i.e., $\mathrm{L}_{\mathrm{Rt}}$ ) and depth of the majority of roots (i.e., $\mathrm{D}_{95}$ ) were as high as for leaf area. These high values may be partly explained by the relatively stable and homogeneous soil environment by using the sand/baked clay substrate filled growth columns. The development of roots occurs in synchrony with shoot growth (Wang et al. 2006), which was reflected by the positive linear relations of $\mathrm{A}_{\mathrm{Lf}}$ with $\mathrm{D}_{95}$ (Fig. 3a, b) and $\mathrm{L}_{\mathrm{Rt}}$ (plot not shown). The heritable traits $\mathrm{L}_{\mathrm{Rt}}$ and $\mathrm{D}_{95}$, therefore, reflect general plant vigor rather than being parameters related to vertical root distribution. This also implies that $\mathrm{D}_{95}$ and $\mathrm{L}_{\mathrm{Rt}}$ alone do not serve lot of new information and selection for a mainly deep reaching root system (i.e. $\mathrm{D}_{95}$ ) could also be practiced by selecting for a vigorous shoot (e.g. $A_{L f}$ ). The effectiveness of such indirect selection can be assessed by calculating the relative efficiency (RE), i.e., the ratio of the indirect response to selection in $\mathrm{D}_{95}$ if selection is performed for $A_{L f}$, over the response in $D_{95}$ if selection is performed for $\mathrm{D}_{95}$ directly. $\mathrm{RE}$ can be calculated following Falconer and Mackay (1996) as

$R E=\frac{i_{A_{L f}} h_{A_{L f}} r_{g}\left(A_{L f}, D_{95}\right)}{i_{D_{95}} h_{D_{95}}}$

where $i$ denotes the selection intensity, $h$ the square root of heritability and $r_{g}$ the genotypic correlation. Assuming the same selection intensities $(i)$ for direct and indirect selection, taking $h^{2}$ values measured at the 6-leaf stage $\left(0.40\right.$ for $\mathrm{A}_{\mathrm{Lf}}, 0.62$ for $\left.\mathrm{D}_{95}\right)$, and $r_{p}\left(\mathrm{~A}_{\mathrm{Lf}}, \mathrm{D}_{95}\right)=0.71$ 
as an estimate for $r_{g}$, this would result in a RE of 0.55 . This means that indirect selection via leaf area would be half as efficient as direct selection for $\mathrm{D}_{95}$. As shoot traits are much easier to assess than rooting depth, the selection intensity and heritability could be more easily be increased for leaf area (i.e. $A_{L f}$ ) compared root traits (i.e. $\mathrm{D}_{95}$ ). Additionally, $r_{g}$ is usually larger than $r_{p}$, wherefore $\mathrm{RE}$ of indirect selection for $\mathrm{D}_{95}$ can be expected to be higher than calculated in our example. According to these considerations, direct screening and selection for deep reaching roots in the growth column system at an early growth stage would not be worthwhile because rooting depth could be selected by direct selection for vigorous shoots. Furthermore, selecting for increased rooting depth by increasing overall vigor may have negative effects for environments with a great risk of terminal drought. According to Ribaut et al. (2009), a typical maize ideotype for such environments has a smaller canopy to allow better light penetration and deeper roots with less lateral branching. Direct selection for such an ideotype may be possible under managed drought and nitrogen stress conditions practiced by CIMMYT (Bänziger et al. 2006).

Relative root distribution has low heritability

DR describes the relative vertical distribution of roots within the soil profile and is less dependent on plant vigor, as indicated by the lack of significant correlations with $\mathrm{A}_{\mathrm{Lf}}, \mathrm{D}_{95}$ and $\mathrm{L}_{\mathrm{Rt}}$. Compared to $\mathrm{DR}_{\mathrm{fix}}$ that showed a strong correlation with $\mathrm{D}_{95}$, DR has the advantage that it is not arbitrary as compared to the situation where a deep root ratio is calculated based on a fix, absolute depth threshold to separate between deep and shallow roots. For example in rice, depth thresholds from $30 \mathrm{~cm}$ (Yadav et al. 1997; Kato et al. 2006) up to $100 \mathrm{~cm}$ (Araki et al. 2000) have been used in field and growth column studies. Such fix thresholds may still be misleading as can be seen for $\mathrm{DR}_{\mathrm{fix}}$ : More vigorous plants are able to place more roots below a certain depth, resulting in larger deep root ratios, independent of their relative root depth distribution. This artifact could be avoided in our study by defining DR in relation to rooting depth where $\mathrm{D}_{95}$ serves as a measure of rooting depth while DR measures the relative distribution.

Although DR showed to be independent of general plant vigor, it was accompanied by a low genetic variation and, consequently, lower heritability estimates at the 6-leaf stage and non-significant genotypic differences in development rates between 2- and 6-leaf stage. Higher heritabilities and more precise genotypic means could be obtained by increasing the number of replications compared to our study. However, this would be accompanied by a largely increased labor demand. The lower genetic control of DR indicates that it will be difficult to change the relative vertical distribution of the root system, i.e. to place relatively more roots at depth without increasing the overall rooting depth.

Influence of allometric root-shoot relationships

We found that genotypes with larger shoots have deeper roots. This is corroborated by Trachsel et al. (2013) reporting a positive correlation between $\mathrm{D}_{95}$ and a vigor proxy measure composed of plant height and SPAD $\left(\mathrm{R}^{2}=0.3\right)$ for field-grown maize under low nitrogen. To avoid the "large plants have deeper roots" problem, we used $\mathrm{A}_{\mathrm{Lf}}-\mathrm{D}_{95}$ to characterize genotypes based on their vertical deviation from the regression line in Fig. 3. Using this deviation seems to be useful for comparing genotypes across environments: Based on four overlapping genotypes (CML444, SC-Malawi, CMLP1 and CMLP2), we found no correlation of our $\mathrm{D}_{95}$ values with those measured by Hund et al. (2009a) $(r=-0.56$; data not shown), but a significant positive correlation between the two studies could be observed for the ratio between $\mathrm{A}_{\mathrm{Lf}}$ and $\mathrm{D}_{95}\left(r=0.96^{*}\right.$; data not shown). However, four genotypes are a small sample and more research is needed to verify if size-dependent rooting depth is a promising trait for selection. It is still not common standard in root research to report basic shoot characteristics and adjust for differences in overall vigor. Doing so would greatly enhance our understanding how root-shoot relationships explain genotype-by-environment interactions. The positive correlation $\left(\mathrm{R}^{2}=0.24\right)$ between rooting depth and vigor (measured as above-ground plant volume) was also reported in a meta-analysis of grasses by Schenk and Jackson (2002).

The question, who wins where and when, may depend on the rooting behavior, water regime and timing. Vigorous genotypes with prolific root growth may benefit from rapid nutrient uptake under well-watered conditions, but might already have extracted available soil water before entering the critical flowering period (Campos et al. 2004). By contrast, genotypes with smaller shoots and relatively deep roots may benefit from water uptake under drought conditions but may 
be too conservative to profit in wet years. In addition, environmental factors such as nitrogen content and soil strength have an effect on the shoot-root relationships. For example, the correlation between plant height and $\mathrm{D}_{95}$ was larger under low compared to high nitrogen conditions (Trachsel et al. 2013) in maize. Furthermore, Acuña and Wade (2013) found a negative relationship between root depth and shoot dry matter on a Calcic Lixisol with a hardpan restricting root growth of wheat varieties.

Can we predict drought behavior by early screening?

A positive association of deep roots with crop performance and drought tolerance has been shown (Passioura 1983; Manschadi et al. 2006; Kirkegaard et al. 2007), but the behavior and performance of different genotypes under drought is influenced by many other factors like shoot architecture, water use efficiency (Passioura 1983), and soil characteristics (Acuña and Wade 2013). The correlations between traits determined in growth columns and in the field in our study have to be interpreted with caution due to the limited extend of the field data (only one season). Field experiments would have to be repeated in different locations/years to make profound statements. In tendency, our low correlations observed (Table 5) indicate limited predictive ability of the growth columns for final plant performance. This seems to be in line with the generally capped correlations between early growth and final plant performance in inbred lines (Mock and McNeill 1979; Strigens et al. 2012) and observations by Watt et al. (2013), who found no correlation between early (5-leaves) and late (flowering) growth stages for the deep rooting trait per se in wheat. Further, a bias of the growth column system, in which roots can be forced to become deep by growing along the growth column wall-substrate interface (Araki et al. 2000), may contribute to the low predictive ability for field performance. Although crown root traits $\left(\mathrm{N}_{\mathrm{Cr}}, \mathrm{D}_{\mathrm{Cr}}, \mathrm{Ang}_{\mathrm{Cr}}\right)$ are less affected by the column growth system, they did not show significant correlations with field performance. Thus, also due to the limited validity of the field data, we were not able to confirm or deny the hypothesis that steep roots are more favorable, granting fast progress of the root system to deeper soil strata (Hammer et al. 2009; Lynch 2013; Trachsel et al. 2013).
Conclusion and outlook

In this experiment, we evaluated root lengths at different, equally spaced column depths. Based on our results, we suggest simplifying this approach in order to gain throughput and, thus, increase the heritability. An increase in replications is necessary, especially for traits like DR, the shoot-to-root ratio and development rates, which have comparably low heritability. Ideally, experiments should cover the range of soil-types, water regimes and fertilization levels representing the target population of environments. As our root distribution data are summarized as three components, i.e. total root lengths, maximum rooting depth and vertical root distribution, we propose measuring these components directly. Maximum rooting depth in soil columns can be measured by removing soil from the bottom upwards until the first root appears. Next, the remaining column can be divided into an upper and lower half and the root of each half can be weighed to determine the total root weight and DR. Eventually, angles of crown may be measured to get information of the potential shallowness of the root system. Finally, basic shoot characteristics need to be measured to determine the stage and environment-specific relationship between root and shoot characteristics.

Acknowledgments The authors would like to thank Claude Welcker from INRA Montpellier for provision of seeds for growth column trials, Jill Cairns for overseeing trials hosted by CIMMYT as well as Vanessa Weber for her technical assistance during data collection and Ciro Sanchez for data collection and management of drought stress trials in the field. This study was supported by the Generation Challenge Programme (Project 15).

\section{References}

Acuña TLB, Wade LJ (2013) Use of genotype x environment interactions to understand rooting depth and the ability of wheat to penetrate hard soils. Ann Bot 112:359-368. doi:10. 1093/aob/mcs 251

Araki H, Hirayama M, Hirasawa H, Iijima M (2000) Which roots penetrate the deepest in rice and maize root systems? Plant Prod Sci 3:281-288. doi:10.1626/pps.3.281

Arlot S, Celisse A (2010) A survey of cross-validation procedures for model selection. Stat Surv 4:40-79. doi:10.1214/09$\mathrm{SS} 054$

Bänziger M, Setimela PS, Hodson D, Vivek B (2006) Breeding for improved abiotic stress tolerance in maize adapted to southern Africa. Agric Water Manage 80:212-224. doi:10.1016/j. agwat.2005.07.014 
Bolanos J, Edmeades G, Martinez L (1993) Eight cycles of selection for drought tolerance in lowland tropical maize. III. Responses in drought-adaptive physiological and morphological traits. Field Crops Res 31:269-286. doi:10.1016/ 0378-4290(93)90066-V

Bonser AM, Lynch J, Snapp S (1996) Effect of phosphorus deficiency on growth angle of basal roots in Phaseolus vulgaris. New Phytol 132:281-288

Campos H, Cooper M, Habben JE et al (2004) Improving drought tolerance in maize: a view from industry. Field Crops Res 90: 19-34. doi:10.1016/j.fcr.2004.07.003

Core Development Team R (2009) R: A language and environment for statistical computing. $\mathrm{R}$ foundation for Statistical Computing, Vienna

Falconer DS, Mackay TF (1996) Introduction to quantitative genetics. Longman Group Limited, Harlow

Gilmour AR, Gogel BJ, Cullis BR, Thompson R (2006) ASReml user guide release 2.0. VSN international Ltd, Hemel Hempstead, HP1 1ES, UK

Hammer GL, Dong Z, McLean G et al (2009) Can changes in canopy and/or root system architecture explain historical maize yield trends in the U.S. Corn Belt? Crop Sci 49:299312. doi:10.2135/cropsci2008.03.0152

Hao XM, Zhang RD, Kravchenko A (2005) Effects of root density distribution models on root water uptake and water flow under irrigation. Soil Sci 170:167-174. doi:10.1097/01.ss. $0000160031.00061 .8 \mathrm{~b}$

Hodge A (2009) Root decisions. Plant, Cell Environ 32:628-640. doi:10.1111/j.1365-3040.2008.01891.x

Hund A, Fracheboud Y, Soldati A et al (2004) QTL controlling root and shoot traits of maize seedlings under cold stress. Theor Appl Genet 109:618-629. doi:10.1007/s00122-004-1665-1

Hund A, Ruta N, Liedgens M (2009a) Rooting depth and water use efficiency of tropical maize inbred lines, differing in drought tolerance. Plant Soil 318:311-325. doi:10.1007/ s11104-008-9843-6

Hund A, Trachsel S, Stamp P (2009b) Growth of axile and lateral roots of maize: I development of a phenotying platform. Plant Soil 325:335-349. doi:10.1007/s11104-009-9984-2

Hund A, Reimer R, Messmer R (2011) A consensus map of QTLs controlling the root length of maize. Plant Soil 344:143-158. doi:10.1007/s11104-011-0735-9

Kato Y, Abe J, Kamoshita A, Yamagishi J (2006) Genotypic variation in root growth angle in rice (Oryza sativa L.) and its association with deep root development in upland fields with different water regimes. Plant Soil 287:117-129. doi:10. 1007/s11104-006-9008-4

Kirkegaard J, Lilley J, Howe G, Graham J (2007) Impact of subsoil water use on wheat yield. Aust J Agr Res 58:303315. doi:10.1071/AR06285

Kumar B, Abdel-Ghani AH, Reyes-Matamoros J et al (2012) Genotypic variation for root architecture traits in seedlings of maize (Zea mays L.) inbred lines. Plant Breed 131:465478. doi:10.1111/j.1439-0523.2012.01980.x

Lebreton C, Lazić-Jančić V, Steed A et al (1995) Identification of QTL for drought responses in maize and their use in testing causal relationships between traits. J Exp Bot 46:853-865. doi:10.1093/jxb/46.7.853

Lorens G, Bennett J, Loggale L (1987) Differences in drought resistance between two corn hybrids. I. Water relations and root length density. Agron J 79:802-807
Ludlow M, Muchow R (1990) A critical evaluation of traits for improving crop yields in water-limited environments. Adv Agron 43:107-153. doi:10.1016/s0065-2113(08)60477-0

Lynch J (1995) Root architecture and plant productivity. Plant Physiol 109:7-13. doi:10.1104/pp.109.1.7

Lynch JP (2013) Steep, cheap and deep: an ideotype to optimize water and $\mathrm{N}$ acquisition by maize root systems. Ann Bot 112: 347-357. doi:10.1093/aob/mcs293

Lynch JP, Ho MD, Phosphorus L (2005) Rhizoeconomics: carbon costs of phosphorus acquisition. Plant Soil 269:45-56. doi: 10.1007/s11104-004-1096-4

Mace ES, Singh V, Van Oosterom EJ et al (2012) QTL for nodal root angle in sorghum (Sorghum bicolor L. Moench) colocate with QTL for traits associated with drought adaptation. Theor Appl Genet 124:97-109. doi:10.1007/s00122-0111690-9

Manavalan LP, Musket T, Nguyen HT (2011) Natural genetic variation for root traits among diversity lines of maize (Zea mays L.). Maydica 56:59-68

Manschadi AM, Christopher J, deVoil P, Hammer GL (2006) The role of root architectural traits in adaptation of wheat to waterlimited environments. Funct Plant Biol 33:823-837. doi:10. 1071/FP06055

Mock J, McNeill M (1979) Cold tolerance of maize inbred lines adapted to various latitudes in North America. Crop Sci 19: 239-242. doi:10.2135/cropsci1979.0011183X001900020017x

Passioura JB (1983) Roots and drought resistance. Agric Water Manage 7:265-280. doi:10.1016/0378-3774(83)90089-6

Patterson HD, Williams ER (1976) A new class of resolvable incomplete block designs. Biometrika 63:83-92

Pierret A, Moran CJ, Doussan C (2005) Conventional detection methodology is limiting our ability to understand the roles and functions of fine roots. New Phytol 166:967-980. doi:10. 1111/j.1469-8137.2005.01389.x

Pommel B, Bouchard C (1990) Effects of seed weight and sowing depth on growth and development of maize seedlings. Agronomie 10:699-708. doi:10.1051/agro:19900901

Ribaut J, Betran J, Monneveux P, Setter T (2009) Drought tolerance in maize. In: Bennetzen JL, Hake SC (eds) Handbook of Maize: Its biology. Springer Science + Business Media, New York, pp 311-344

Richards R, Rebetzke G, Appels R, Condon A (2000) Physiological traits to improve the yield of rainfed wheat: can molecular genetics help? In: Ribaut JM, Poland D (eds) Molecular approaches for the genetic improvement of cereals for stable production in water-limited environments. A strategic planning workshop held at CIMMYT. El Batan, Mexico, pp 54-58

Sattelmacher B, Klotz F, Marschner H (1983) Vergleich von zwei nicht-destruktiven Methoden zur Bestimmung von Wurzeloberflächen. Z Pflanz Bodenkunde 146:449-459. doi:10.1002/jpln.19831460406

Schenk HJ, Jackson RB (2002) The global biogeography of roots. Ecol Monogr 72:311-328. doi:10.2307/3100092

Strigens A, Grieder C, Haussmann BIG, Melchinger AE (2012) Genetic variation among inbred lines and testcrosses of maize for early growth parameters and their relationship to final dry matter yield. Crop Sci 52:1084-1092. doi:10.2135/ cropsci2011.08.0426

Trachsel S, Messmer R, Stamp P, Hund A (2009) Mapping of QTLs for lateral and axile root growth of tropical maize. 
Theor Appl Genet 119:1413-1424. doi:10.1007/s00122009-1144-9

Trachsel S, Kaeppler SM, Brown KM, Lynch JP (2011) Shovelomics: high throughput phenotyping of maize (Zea mays L.) root architecture in the field. Plant Soil 341:75-87. doi:10.1007/s11104-010-0623-8

Trachsel S, Kaeppler SM, Brown KM, Lynch JP (2013) Maize root growth angles become steeper under low $\mathrm{N}$ conditions. Field Crops Res 140:18-31. doi:10.1016/j.fcr.2012.09.010

Tuberosa R, Sanguineti MC, Landi P et al (2002) Identification of QTLs for root characteristics in maize grown in hydroponics and analysis of their overlap with QTLs for grain yield in the field at two water regimes. Plant Mol Biol 48:697-712. doi: 10.1023/A:1014897607670

van Beem J, Smith M, Zobel R (1998) Estimating root mass in maize using a portable capacitance meter. Agron J 90:566570. doi:10.2134/agronj1998.00021962009000040021x

Van Staveren JP, Stoop WA (1985) Adaptation to toposequence land types in West Africa of different sorghum genotypes in comparison with local cultivars of sorghum, millet, and maize. Field Crops Res 11:13-35. doi:10.1016/03784290(85)90089-9
Wan C, Xu W, Sosebee RE et al (2000) Hydraulic lift in droughttolerant and -susceptible maize hybrids. Plant Soil 219:117126. doi:10.1023/A:1004740511326

Wang H, Inukai Y, Yamauchi A (2006) Root development and nutrient uptake. Cri Rev Plant Sci 25:279-301. doi:10.1080/ 07352680600709917

Watt M, Moosavi S, Cunningham SC et al (2013) A rapid, controlled-environment seedling root screen for wheat correlates well with rooting depths at vegetative, but not reproductive, stages at two field sites. Ann Bot 112:447-455. doi: 10.1093/aob/mct122

Yadav R, Courtois B, Huang N, McLaren G (1997) Mapping genes controlling root morphology and root distribution in a doubled-haploid population of rice. Theor Appl Genet 94: 619-632. doi:10.1007/s001220050459

Yu G-R, Zhuang J, Nakayama K, Jin Y (2007) Root water uptake and profile soil water as affected by vertical root distribution. Plant Ecol 189:15-30. doi:10.1007/s11258-006-9163-y

Zhu J, Kaeppler SM, Lynch JP (2005) Mapping of QTLs for lateral root branching and length in maize (Zea mays L.) under differential phosphorus supply. Theor Appl Genet 111:688-695. doi:10.1007/s00122-005-2051-3 